\title{
Determinants of BDNF-induced Hippocampal Synaptic Plasticity: Role of the Trk B Receptor and the Kinetics of Neurotrophin Delivery
}

\author{
Hyejin Kang, Lin Z. Jia, Ki-Young Suh, Lixin Tang, and Erin M. Schuman' \\ Division of Biology 216-76 \\ California Institute of Technology \\ Pasadena, California 91125
}

\begin{abstract}
The neurotrophins are a class of signaling molecules known for their growth and survival-promoting activities during neuronal development. Recent studies suggest that the neurotrophins, including brain-derived neurotrophic factor (BDNF), can also dramatically influence synaptic transmission in the adult hippocampus. The experiments described in this paper indicate that ability of BDNF to potentiate synaptic transmission in the hippocampus relies on functional Trk $B$ receptors. Moreover, the rate at which BDNF is applied to hippocampal synapses is also a potent determinant of whether synaptic potentiation will result. Hippocampal slices perfused with BDNF at a very slow flow rate (e.g., $\leqslant 25 \mathrm{ml} / \mathrm{hr}$ ) did not show synaptic potentiation. Increasing the rate of BDNF application resulted in synaptic potentiation in which the magnitude and onset kinetics of the potentiation were determined by the rate of BDNF delivery. Immunocytochemical analysis of BDNF detected with confocal microscopy confirmed these electrophysiological observations, indicating that the penetration of BDNF into hippocampal slices is influenced dramatically by the perfusion rate.
\end{abstract}

\section{Introduction}

The ability of the brain to alter information processing by changing the structure and strength

${ }^{1}$ Corresponding author. of synaptic connections is essential for the successful development and survival of organisms. There is increasing evidence that the central nervous system (CNS) uses some of the same molecular mechanisms during both developmental and adult plasticity (Goodman and Shatz 1993). The neurotrophins, including nerve growth factor (NGF), brain-derived neurotrophic factor (BDNF), and NT-3, are proteins that promote the survival and differentiation of some neurons during development. Although the neurotrophins are known primarily for their growth-promoting activities during neuronal development, recent studies suggest that they can also influence synaptic transmission and plasticity (for review, see Lo 1995; Thoenen 1995).

Lohof et al. (1993) were the first to demonstrate an acute effect of neurotrophins on synaptic transmission. They applied neurotrophins to developing frog nerve-muscle synapses in culture and showed that BDNF and NT-3 can enhance both evoked synaptic responses as well as the frequency of miniature synaptic events (Lohof et al. 1993). Subsequent studies in hippocampal cell cultures have documented similar findings (Lessmann et al. 1994; Levine et al. 1995).

In previous studies, we demonstrated an enhancement of synaptic transmission in hippocampal slices produced by the application of BDNF or NT-3 in the extracellular bathing medium (Kang and Schuman 1995b, 1996). The synaptic potentiation produced by the neurotrophins was very rapid in onset $(10-20 \mathrm{~min})$ and long-lasting (hours). In this previous study, the rate of perfusion of the slice was $\sim 200-250 \mathrm{ml} / \mathrm{hr}$. BDNF is not very diffusible owing to its basic nature (Leibrock et al. 1989) and, perhaps, the abundance of both full-length and truncated Trk receptors (Zhou et

LEARNING \& MEMORY 3:188-196 (c) 1996 by Cold Spring Harbor Laboratory Press ISSN1072-0502/96 \$5.00

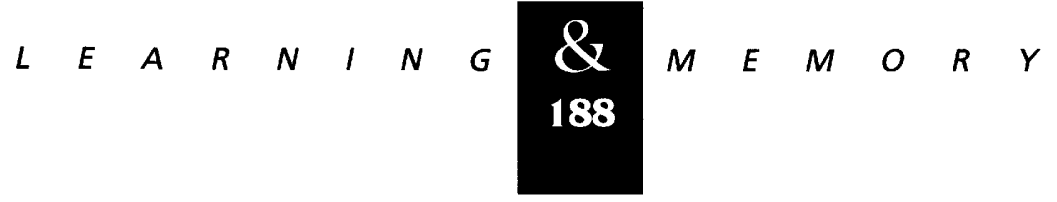


al. 1993; Escandon et al. 1994). In this study, we have examined the effects of perfusion rate on both the kinetics and the magnitude of the enhancement produced by BDNF. Using immunocytochemical techniques and confocal microscopy, we have also examined the penetration of BDNF into hippocampal slices as a function of perfusion rate.

Does exogenously applied BDNF work through the same signal transduction mechanisms used by BDNF to bring about changes in survival during neuronal development? In situ hybridization studies have shown that Trk $B$, the primary receptor for $\mathrm{BDNF}$, is expressed in all the CA fields, in dentate granule cells, as well as in interneurons (Merlio et al. 1992; Ip et al. 1993). Our previous study (Kang and Schuman 1995b) demonstrated that the receptor tyrosine kinase inhibitor K252a blocked the synaptic potentiation produced by BDNF. However, K252a has also been reported to block other classes of protein kinases (Kase et al. 1987). To ascertain specifically the role of Trk B, we examined whether pretreatment of hippocampal slices with a function-blocking Trk $B$ antibody can prevent BDNF-induced potentiation.

\section{Materials and Methods}

\section{SLICE PREPARATION, ELECTROPHYSIOLOGY, AND ANALYSIS}

Hippocampal slices were prepared using a Stoelting tissue chopper from young ( $6-8$ weeks) adult male Sprague-Dawley rats. Before electrophysiological recording, slices were stored for at least $1.5 \mathrm{hr}$ on a Millipore membrane (no. 1) placed over a tissue culture dish containing oxygenated Ringer's solution. The top of the slice was exposed to $95 \% \mathrm{O}_{2}$ and $5 \% \mathrm{CO}_{2}$ circulating in an enclosed chamber. For electrophysiological recordings, slices were submerged in a stream of ACSF (119 mM NaCl, $2.5 \mathrm{~mm} \mathrm{KCl,} 1.3 \mathrm{~mm} \mathrm{MgSO}_{4}$, $2.5 \mathrm{~mm} \mathrm{CaCl} 2,1.0 \mathrm{~mm} \mathrm{NaH} \mathrm{PO}_{4}, 26.2 \mathrm{~mm}$ $\mathrm{NaHCO}_{3}$, and $11.0 \mathrm{~mm}$ glucose) maintained at room temperature $\left(22-25^{\circ}\right)$ and gassed with $95 \%$ $\mathrm{O}_{2}$ and $5 \% \mathrm{CO}_{2}$. In different sets of experiments, the solution flow rate was varied between 25 and $250 \mathrm{ml} /$ hour. Field excitatory postsynaptic potentials (EPSPs) measured in stratum radiatum were evoked by stimulation of the Schaffer collateral- commissural afferents ( 1 stimulation every 15 sec); the initial slope was measured. The maximal potentiation, time to a $25 \%$ increase, and slope of potentiation onset were calculated for each individual experiment, relative to baseline measurements before BDNF application. The slope of potentiation onset was calculated for each experiment by linear regression analysis of all data points between the time of BDNF application and the maximal potentiation. To assess statistical significance, paired $t$-tests, comparing the average slope size for $10 \mathrm{~min}$ before BDNF to either 50-60 or 170-180 min after BDNF application, were performed on non-normalized data. In addition, a oneway analysis of variance (ANOVA) was conducted between perfusion groups for the maximum potentiation, time to $25 \%$ increase, and the slope of potentiation onset. [Significance levels are as stated in the text; $P$ values $>0.05$ are designated as not significant (ns)].

\section{BLOCKING ANTIBODY EXPERIMENTS}

The function-blocking Trk B antibody, which blocks BDNF-induced phosphorylation of Trk B receptors in $3 \mathrm{~T} 3$ cells, was kindly provided by Andy Welcher (Amgen). Before electrophysiological recording, slices were incubated individually for 2-3 hr. in single wells of a 24-well tissue culture plate in $200 \mu$ l of Ringer's solution containing either a Trk B antibody (1:10) or an equivalent dilution of preimmune serum. The culture plate was placed in an oxygenated chamber. Slices were then transferred to a recording chamber, submerged, and perfused with normal Ringer's solution for $\sim 30$ min before the addition of BDNF.

\section{NEUROTROPHIN APPLICATION AND HANDLING}

Great care was taken in the application and storage of the BDNF. BDNF (generous gift from Amgen) was kept at $4^{\circ} \mathrm{C}$. Phosphate buffer stock solutions were made every 1-3 days and kept at $4^{\circ} \mathrm{C}$. New supplies of BDNF were obtained on a regular basis (every 2-4 months) as it was observed occasionally that individual stocks became less potent over time. The neurotrophins were added directly to the perfusion ACSF. The perfusion apparatus was modified to include chemically inert materials-silicon tubing (OD 0.183 inches; ID 0.132 inches) and a Teflon beaker.

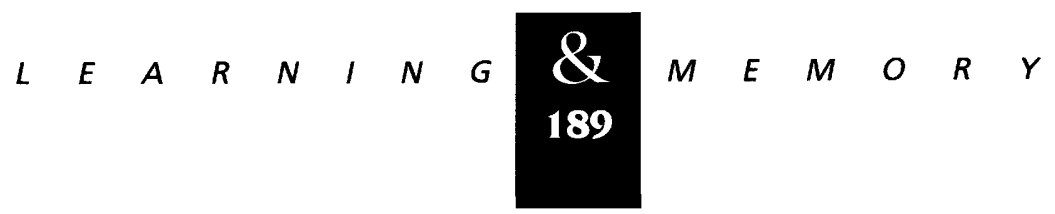


Kang et al.

\section{IMMUNOCYTOCHEMISTRY AND CONFOCAL MICROSCOPY}

Following electrophysiology and BDNF perfusion, slices were fixed in $4.0 \%$ paraformaldehyde and $0.2 \%$ glutaraldehyde for $4 \mathrm{hr}$ and then transferred to PBS. Individual slices were then cut into $50 \mu \mathrm{M}$ sections, permeabilized with $0.7 \%$ Triton $\mathrm{X}-100$ for $1 \mathrm{hr}$, and incubated in primary antibody [ $1: 100$ in $5 \%$ rabbit serum in $\mathrm{h}-\mathrm{PBS}+0.5 \%$ Triton $\mathrm{X}-100$ (preblock)] overnight at $4^{\circ} \mathrm{C}$. Sections were washed in preblock solution and then incubated in secondary antibody for $1 \mathrm{hr}$ at room temperature (1:100 in preblock solution) and then rinsed and mounted on glass slides. The primary antibody used was a chicken antihuman BDNF (Promega); the secondary antibody was a fluorescein-conjugated rabbit antichicken (Jackson Labs). For immunostaining for function-blocking Trk B antibody, slices were fixed and sectioned as indicated above at 0,30 , or $60 \mathrm{~min}$ following perfusion with normal Ringer's solution in the electrophysiology recording chamber. The protocol for immunostaining with the secondary antibody was the same as above. Following immunostaining, confocal images were obtained with a Zeiss 310 confocal laser-scanning microscope. The $488-\mathrm{nm}$ line of an argon-ion laser attenuated to $1 / 10$ of the maximal intensity with a neutral density filter was used to excite fluorescein. Images were visualized with either a $10 \times$ objective (Plan-NeoFluor, n.a. 0.30, Zeiss) or a $63 \times \mathrm{X}$ oil immersion objective (PlanApochromat, n.a. 1.40 Zeiss). Brightness and contrast settings were kept constant for all images taken within a given set of experiments. For BDNF visualization the following settings were used: contrast, 420; brightness, 9800; pinhole, 40. For Trk B antibody staining the following settings were used: contrast, 320; brightness, 9800; pinhole, 40 .

\section{Results}

\section{FUNCTION-BLOCKING TRK ANTIBODIES}

The dependence of BDNF-induced potentiation on Trk B function was assessed using function-blocking Trk $B$ antibodies. We confirmed the penetration of the Trk B antibody into the depth of the slice using fluorescent secondary antibodies and confocal microscopy. After $1 \mathrm{hr}$ of washing slices with antibody-free Ringer's solution there was still an substantial amount of Trk $B$ antibody detected throughout the slice (Fig. 1A,B). Slices exposed to the Trk $B$ antibody before BDNF treatment $(50 \mathrm{ng} / \mathrm{ml}-165 \mathrm{ml} / \mathrm{hr}$ ) exhibited greatly diminished BDNF-induced potentiation relative to control slices incubated in preimmune serum [mean percent of baseline \pm s.E.M.: Trk B:
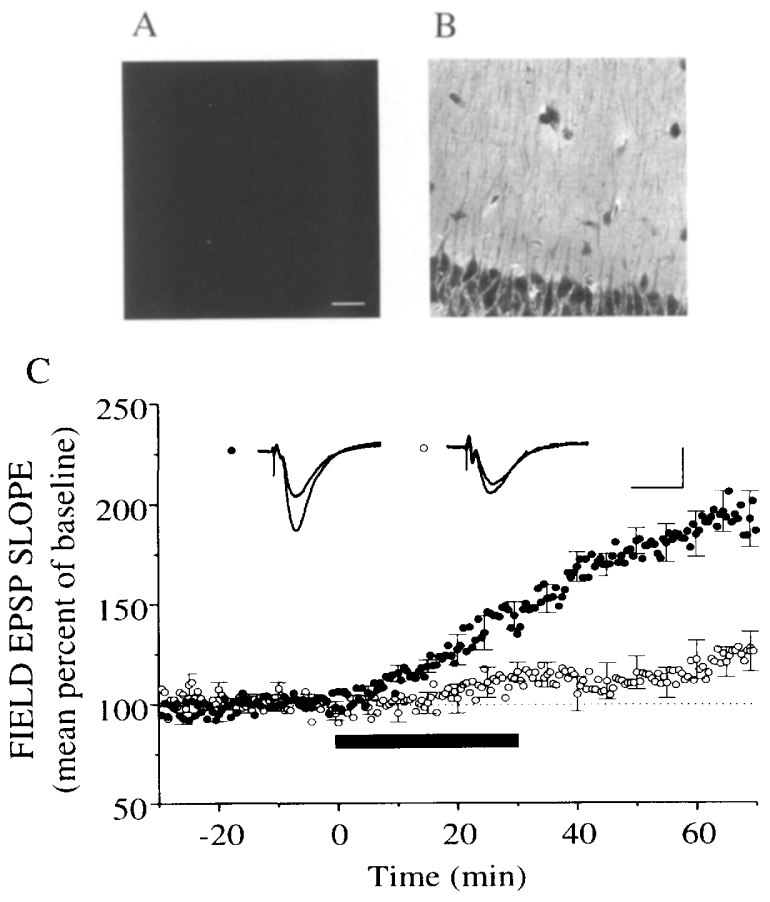

Figure 1: Function-blocking Trk B antibodies penetrate hippocampal slices and prevent BDNF-induced synaptic potentiation. (A) A $63 \times$ confocal image to secondary antibody in the absence of primary antibody. Bar, 25 $\mu \mathrm{m}$. (B) A $63 \times$ confocal image of the CA1 region from a slice exposed to a function-blocking Trk B antibody for $2 \mathrm{hr}$ and then perfused with normal Ringer's solution in the recording chamber for $60 \mathrm{~min}$. Positive antibody staining is indicated by the color white. This image was taken from a section $150 \mu \mathrm{m}$ from the surface of the slice. (C) Ensemble averages for experiments in which slices were preincubated in either a function-blocking Trk B antibody or an equivalent dilution of preimmune serum before electrophysiological recording. BDNF (50 $\mathrm{ng} / \mathrm{ml}$ ) was applied for time indicated by the solid bar. In the Trk B antibody treated slices the mean field EPSP slope before BDNF was $0.11 \pm 0.01 \mathrm{mV} / \mathrm{msec}$ (mean \pm S.E.M.) and $0.12 \pm 0.01 \mathrm{mV} / \mathrm{msec} 50-60 \mathrm{~min}$ after BDNF. In the preimmune serum-treated slices the mean field EPSP slope before BDNF was $0.11 \pm 0.01$ $\mathrm{mV} / \mathrm{msec}$ and $0.19 \pm 0.03 \mathrm{mV} / \mathrm{msec}$ after BDNF. Two superimposed representative field EPSPs are shown for each group, $5 \mathrm{~min}$ before and $60 \mathrm{~min}$ after BDNF application. Calibration bar, $1 \mathrm{mV}, 20 \mathrm{msec}$.

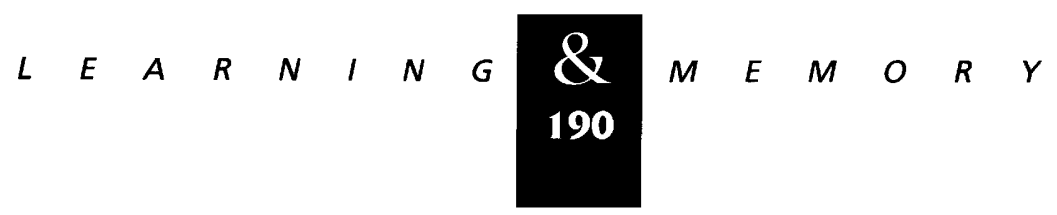


113.3 $\pm 6.3(n=9)$; control: $181.4 \pm 7.9(n=9)$ ] (Fig. 1C). Slices pretreated with the Trk $B$ antibody failed to exhibit significant potentiation, whereas the BDNF-induced enhancement in control slices was statistically significant $(P<0.001)$. These results indicate that BDNF requires functional Trk B receptors to potentiate synaptic transmission in the hippocampal slice.

\section{RATE OF BDNF DELIVERY: EFFECTS ON SYNAPTIC PLASTICITY}

The ability of BDNF to potentiate synaptic transmission was examined at six different perfusion rates: $25,50,80-95,110-140,160-180$, and $220-250 \mathrm{ml} / \mathrm{hr}$. In individual experiments, the rate of perfusion was constant and was not changed before, during, or after the application of BDNF. Control experiments, in which no BDNF was applied, were also conducted for each perfusion rate. For each experiment, three variables were analyzed: the maximum potentiation achieved following BDNF application, the time to a $25 \%$ increase in synaptic strength, and the slope of potentiation onset. The onset slope was calculated for all data points beginning with the initial BDNF application and ending with the maximum potentiation value for a given experiment.

There was a significant effect of the perfusion rate on all of the indices of BDNF-induced enhancement examined. Ensemble averages of experiments conducted at four different perfusion rates and their associated controls are shown in Figure 2. At slowest flow rate examined, $25 \mathrm{ml} / \mathrm{hr}$, BDNF did not produce a consistent enhancement of synaptic transmission (Fig. 2A). A modest potentiation of synaptic transmission was often observed in experiments with perfusion rates of 50 (Fig. 2B) and $80 \mathrm{ml} / \mathrm{hr}$; the enhancement for these groups, however, failed to reach statistical significance, likely attributable to the small sample size. At the 110-140 (Fig. 2C), 160-180 (Fig. 2D), and 220-240 perfusion rates, BDNF induced a significant increase in synaptic strength $(P<0.05$ for all groups). In comparison, control experiments conducted at identical flow rates did not show any significant enhancement (Fig. 2E-H). Only 1 of 13 control experiments (conducted at different perfusion rates) exhibited an increase of synaptic transmission $>10 \%$ [mean percent of base line (all controls ) at $80-90 \mathrm{~min}: 96.0 \pm 2.5 \%$ ].

As shown in Figure 3, increasing the perfusion

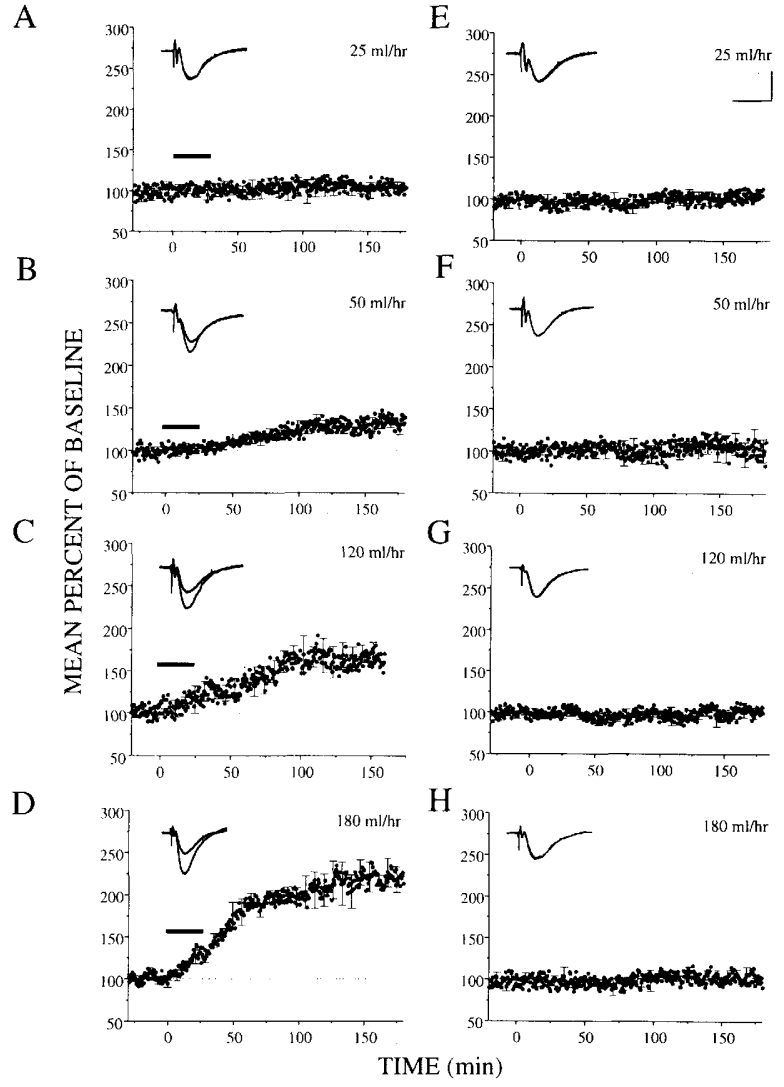

Figure 2: The influence of rate of perfusion on BDNFinduced synaptic potentiation. Ensemble averages for sets of experiments conducted at different perfusion rates are shown. $(A-D)$ Ensemble averages for experiments in which BDNF $(50 \mathrm{ng} / \mathrm{ml})$ was applied for 30 min, as indicated by the solid bar. $(E-H)$ Control experiments conducted at identical perfusion rates, in which a sham solution addition of PBS was performed in lieu of BDNF addition. Perfusion rates are indicated in the upper right-hand corner of each graph. The sample sizes for the graphs in A-H shown are as follows: $n=4,5,4$, $6,3,3,4$, and 3 , respectively. In all panels two superimposed representative field EPSPs are shown, $5 \mathrm{~min}$ before and $160 \mathrm{~min}$ after BDNF application. EPSPS shown in control experiments are taken from equivalent time points. Calibration bar, $1 \mathrm{mV}, 20 \mathrm{msec}$.

rate increased both the onset kinetics and the maximum potentiation produced by BDNF. The maximum potentiation (Fig. 3A) increased as a function of perfusion rate; the enhancement was the smallest (nonsignificant) for the slowest ( 25 $\mathrm{ml} / \mathrm{hr}$ ) flow rate and largest for the fastest (220-240 $\mathrm{ml} / \mathrm{hr}$ ) flow rate (mean percent of baseline: $25 \mathrm{ml} / \mathrm{hr}$ : $114.0 \pm 4.8 \% ; 220-240 \mathrm{ml} / \mathrm{hr}$ : $281.2 \pm 32.8 \%$ ). Intermediate perfusion rates (e.g., $50-140 \mathrm{ml} / \mathrm{hr}$ ) yielded BDNF-induced potentia-

$$
\begin{array}{llllllll}
L & E & A & R & N & I & N & G \\
\begin{array}{c}
\boldsymbol{Q} \\
191
\end{array} & M & E & M & O & R & Y
\end{array}
$$


Kang et al.

A

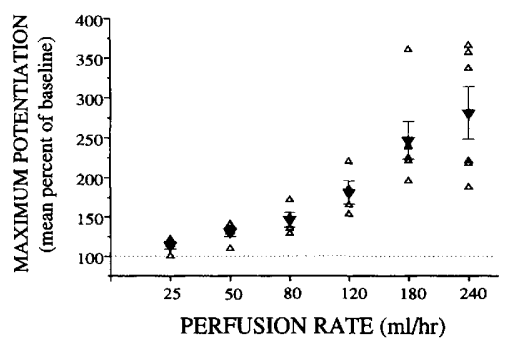

B

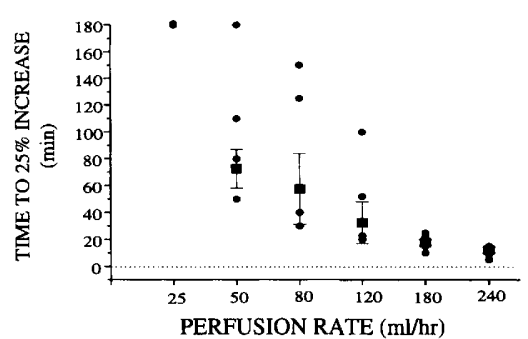

C

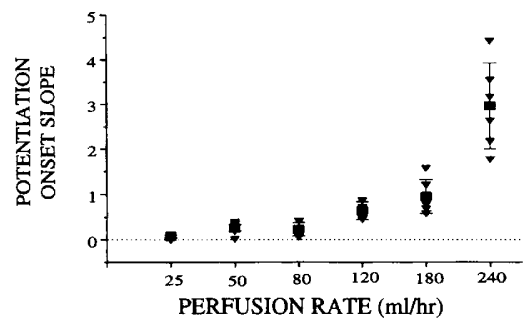

Figure 3: The perfusion rate affects the maximum potentiation, time to $25 \%$ increase, and slope of potentiation onset. Shown are scatter plots of individual experiments conducted at different perfusion rates. For each perfusion rate the mean \pm S.E.M. is indicated by the large symbol with the error bars. (A) Plot depicting the relationship between maximum potentiation and perfusion rate. $(B)$ Plot depicting the relationship between time to $25 \%$ increase and perfusion rate. (C) Plot depicting the relationship between the potentiation onset slope (see Materials and Methods) and perfusion rate.

tion values between those observed for the slowest and fastest rates. An ANOVA comparing the maximum potentiation between groups indicated a significant effect of perfusion rate $(P<0.01)$.

The time to a $25 \%$ increase in synaptic strength (Fig. 3B) decreased as a function of perfusion rate. None of the experiments conducted at $25 \mathrm{ml} / \mathrm{hr}$ exhibited a $25 \%$ increase in synaptic strength; for graphical purposes each of these experiments is assigned a maximum value of $180 \mathrm{~min}$ in Figure 3B. As the perfusion rate increased across groups, the time required to achieve a $25 \%$ enhancement of synaptic strength decreased; for the slowest group $(50 \mathrm{ml} / \mathrm{hr})$ that exhibited a $25 \%$ increase the mean time was $80.0 \pm 27.0 \mathrm{~min}$ and for the fastest $(220-240 \mathrm{ml} / \mathrm{hr}$ ) group the mean time was $12.2 \pm 2.1 \mathrm{~min}$. Increasing the flow rate also decreased the variability between individual experiments within a given group, perhaps reflecting a more reliable delivery of BDNF at faster perfusion rates. An ANOVA comparing the time to $25 \%$ increase between the groups indicated a significant effect of perfusion rate $(P<0.01)$.

The slope of the potentiation onset was also affected by the perfusion rate: The slower the perfusion, the slower the onset of the synaptic enhancement. The mean slope value (mean percent of baseline $/ \mathrm{min}$ ) for the slowest perfusion group $(25 \mathrm{ml} / \mathrm{hr}$ ) was $0.08 \pm 0.03$ and for the fastest (220-240 $\mathrm{ml} / \mathrm{hr}$ ) perfusion group was $2.98 \pm 0.97$. An ANOVA comparing the onset slope between groups indicated a significant effect of perfusion rate $(P<0.01)$. These data indicate that the rate at which BDNF is introduced into the slice influences how quickly synaptic potentiation reaches its maximal value.

\section{BDNF SLICE PENETRATION: IMMUNOSTAINING AND CONFOCAL MICROSCOPY}

Do the observed effects of perfusion rate on BDNF-induced synaptic enhancement reflect differences in the ability of BDNF to penetrate the slice? To address this issue, we examined the penetration of BDNF into hippocampal slices as a function of the perfusion rate using immunocytochemistry and confocal microscopy. The first issue we addressed is whether the perfusion rate also influences significantly the rate at which BDNF is introduced to the slice. This was explored by examining BDNF immunostaining at different time points following its addition using either the slowest $(25 \mathrm{ml} / \mathrm{hr})$ or the fastest $(220 \mathrm{ml} / \mathrm{hr})$ perfusion rates used in the electrophysiology studies. We focused our analysis on sections 150-300 $\mu \mathrm{m}$ into the depth of the slice. As shown in Figure $4 \mathrm{~A}$ and $D$, there was a small amount of endogenous BDNF detected in control slices placed in the recording chamber but not exposed to exogenous BDNF. The perfusion rate significantly affected the kinetics of BDNF penetration into the slice at all time points examined. In slices fixed $15 \mathrm{~min}$ after the addition of BDNF, there was a clear increase in the amount of BDNF in the slice perfused at the fast flow rate (Fig. 4E), whereas there was no obvious increase in BDNF detected in the slice perfused at the slow rate (Fig. $4 \mathrm{~B}$ ). This observation is consistent with the increase in synaptic strength evident

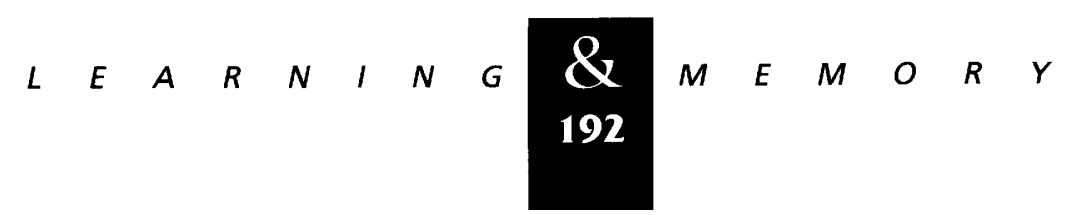



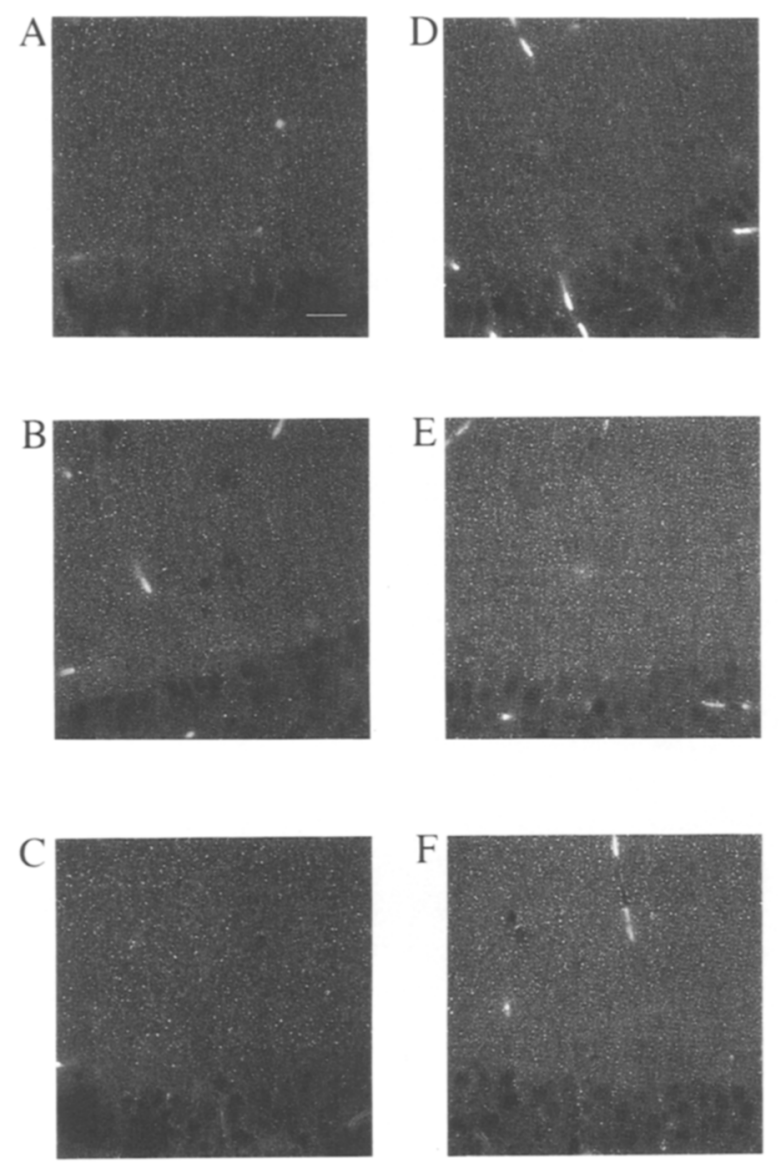

Figure 4: Fast perfusion rates increase the rate of BDNF penetration into hippocampal slices. Slices exposed to a slow $(25 \mathrm{ml} / \mathrm{hr})$ or fast $(220 \mathrm{ml} / \mathrm{hr})$ flow rate were examined for BDNF immunoreactivity before BDNF addition (endogenous BDNF staining only), and $15 \mathrm{~min}$ or $45 \mathrm{~min}$ after BDNF addition. Each panel shows a $63 \times$ confocal image of the $\mathrm{CA} 1$ region of a hippocampal slice stained with an antibody to BDNF. The cell bodies (stratum pyrimidale) are oriented horizontally across the bottom of each image with the apical dendrites of the CA1 neurons extending up, vertically in the stratum radiatum. The images shown are on a blackwhite scale, where black indicates absence of immunoreactivity and changes from black (e.g., gray to white) indicate the presence of immunoreactivity. Therefore, BDNF immunoreactivity is indicated by both the brightest spots and the overall brightness of the image. (A-C) BDNF immunoreactivity in slices perfused at $25 \mathrm{ml} / \mathrm{hr}$.

(A) Control immunostaining for endogenous BDNF, staining is most evident in the stratum radiatum. Bar, 25 $\mu \mathrm{m}$. (B) Immunostaining in a slice exposed to BDNF for $15 \mathrm{~min}$. (C) Immunostaining in a slice exposed to BDNF for $45 \mathrm{~min}$. (D-F) BDNF immunoreactivity in slices perfused at $220 \mathrm{ml} / \mathrm{hr}$. (D) Control immunostaining for endogenous BDNF. $(E)$ Immunostaining in a slice exposed to BDNF for $15 \mathrm{~min}$. $(F)$ Immunostaining in a slice exposed to BDNF for $45 \mathrm{~min}$. within $15 \mathrm{~min}$ in the fast flow rate electrophysiology experiments (e.g., Fig. 2D; Kang and Schuman $1995 \mathrm{~b}$ ) and the absence of such an increase in the slow rate electrophysiology experiments (Fig. 2A). Slices fixed $45 \mathrm{~min}$ after BDNF addition ( 15 min into the washout period) showed no further increase in immunoreactivity for the fast flow rate (Fig. 4E vs. F) and, perhaps, a very small increase for the slower flow rate (Fig. 4B vs. C). Therefore, increasing the perfusion rate increases the rate at which BDNF penetrates the interior of the slice.

In the second set of experiments, all slices that had been exposed previously to BDNF were fixed at the termination of electrophysiological recording. Confocal images were taken of slices perfused at several different rates. Slices treated with a fluorescent secondary antibody in the absence of a primary antibody showed negligible background staining (Fig. 5A). (Note that the bright horizontally oriented blobs, evident in Fig. 5 as well as Fig. 4 , are blood vessels that react nonspecifically with the secondary antibody.) As observed above, there was a small amount of endogenous BDNF detected in control slices placed in the recording chamber but not exposed to exogenous BDNF (cf. Fig. 5A and $B$ ). Control experiments revealed that the level of endogenous BDNF observed over time did not appear to change as a function of perfusion rate (data not shown). As shown in Figure 5C-F, there was a dramatic effect of flow rate on the incorporation of exogenous BDNF into the slice. Increasing the perfusion rate increased the absolute quantity of BDNF that penetrated the tissue successfully. This is indicated by the increase in the punctate clusters of staining as well as the increase in the overall number of white pixels evident in the background across the different panels.

\section{Discussion}

The electrophysiological data shown above indicate that functional Trk $B$ receptors are required for BDNF-induced synaptic potentiation. In addition, our examination of several different perfusion rates indicates that the rate of BDNF delivery is an important determinant of both the magnitude and the kinetics of BDNF-induced synaptic potentiation. At the slowest perfusion rate examined, no significant synaptic potentiation was observed. Increasing the rate of perfusion to higher rates, however, resulted in a BDNF-induced potentiation whose magnitude and steepness of onset was related significantly to the speed of application.

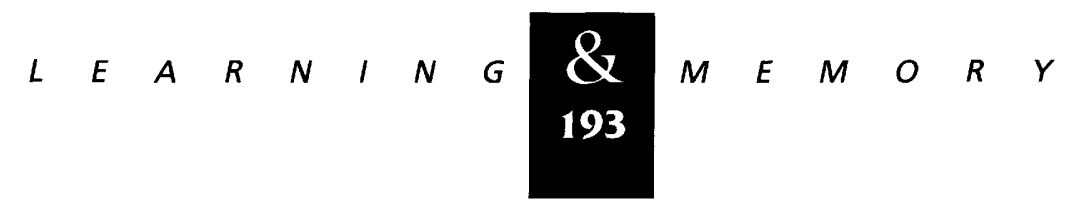



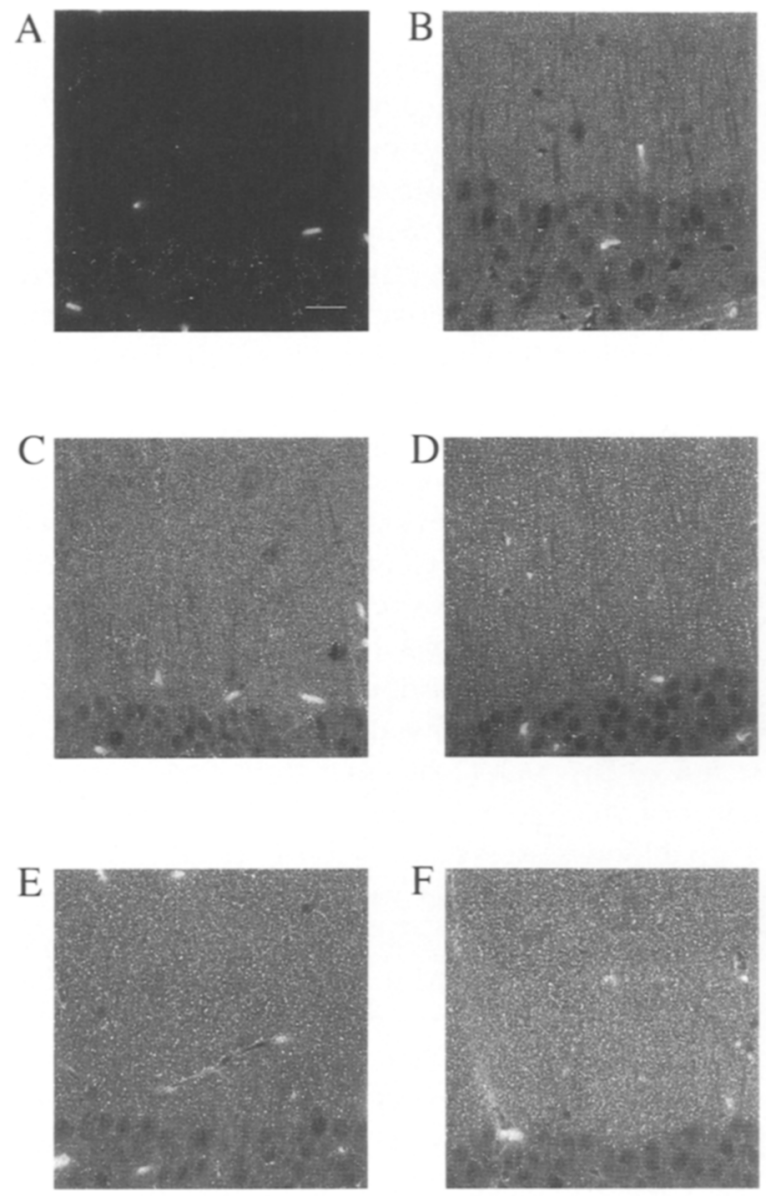

Figure 5: Faster perfusion rates increase the absolute penetration of BDNF into hippocampal slices. Images are from slices used in electrophysiological experiments exposed to BDNF for $30 \mathrm{~min}$ at the perfusion rates indicated below. All slices shown here were fixed $170 \mathrm{~min}$ following BDNF application. (A) Control experiment in which the slice was not exposed to primary antibody but was exposed to the secondary antibody. Bar, $25 \mu \mathrm{m}$. $(B)$. Control immunostaining for endogenous BDNF in a slice, staining is most evident in the stratum radiatum. (C) Slice exposed to BDNF at a perfusion rate of 50 $\mathrm{ml} / \mathrm{hr}$. A small increase in the magnitude of staining over control $(B)$ is evident, particularly in the dendritic region. This slice exhibited a maximum potentiation of $140.0 \%$ of baseline following exposure to BDNF. (D) Slice exposed to BDNF at a perfusion rate of $90 \mathrm{ml} / \mathrm{hr}$. A clear increase in staining relative to the previous panels is evident. This slice exhibited a maximum potentiation of $156.0 \%$ of baseline following exposure to BDNF. (E) Slice exposed to BDNF at a perfusion rate of $145 \mathrm{ml} / \mathrm{hr}$. This slice exhibited a maximum potentiation of $165.0 \%$ of baseline following exposure to BDNF. $(F)$ Slice exposed to BDNF at a perfusion rate of $210 \mathrm{ml} / \mathrm{hr}$. Note that this slice exhibits the most abundant staining for BDNF. This slice exhibited a maximum potentiation of $360.0 \%$ of baseline following exposure to BDNF.
Our immunohistochemical data indicate that the perfusion rate potently influences the amount of exogenous BDNF detected in the slice. These data suggest that faster perfusion rates increase the levels of BDNF that reach the slice interior. Given the volume of our recording chamber, we estimate that BDNF reaches an equilibrium concentration in the chamber in $\sim 1 \mathrm{~min}$ and $10-15 \mathrm{~min}$, respectively, for the fast and slow perfusion rates. If this initial difference accounts for the observed difference in BDNF penetration, then we would expect that the levels of BDNF observed at $45 \mathrm{~min}$ at 25 $\mathrm{ml} / \mathrm{hr}$ (Fig. 4C) should be at least as high as those observed at $15 \mathrm{~min}$ at $220 \mathrm{ml} / \mathrm{hr}$ (Fig. 4E). Clearly, this is not the case. Therefore, the flow rate itself appears to influence the ease with which BDNF penetrates the slice.

The flow rate also influences the maximal amount of BDNF that enters the tissue. Given that BDNF is only applied for $30 \mathrm{~min}$, this observation may be explained by the fact that BDNF enters the tissue more quickly at faster perfusion rates. The data shown in Figure 5 were taken $\sim 2$ hr after BDNF washout. It is important to note that the immunostaining procedure we used involves membrane permeabilization before treatment with the primary antibody to BDNF. As such, we cannot distinguish between extracellularly versus intracellularly localized BDNF in these experiments. Moreover, we also cannot rule out the possibility that exogenous BDNF can increase the synthesis of endogenous BDNF. Can the persistence of BDNF staining in Figure 5 account for the persistence of the BDNF-induced potentiation? Our earlier experiments suggest that this is not the case. The application of the receptor kinase inhibitor $\mathrm{K} 252 \mathrm{a}$ after the initiation of BDNF-induced enhancement did not result in a return to basal levels of synaptic transmission, suggesting that new BDNF-Trk interactions are not responsible for the maintenance phase of the synaptic enhancement. We are currently addressing this issue biochemically by monitoring the extent of BDNF-induced Trk B phosphorylation during early and late aspects of the synaptic enhancement.

Does the maximal values of BDNF delivered to the tissue determine whether potentiation will occur or is it the rate itself that is important? At the slowest flow rate examined here $(25 \mathrm{ml} / \mathrm{hr})$ we did not observe any significant potentiation of synaptic transmission, although our confocal studies indicate that some BDNF penetrated the slice at this slow flow rate (Fig. 4). We observed that

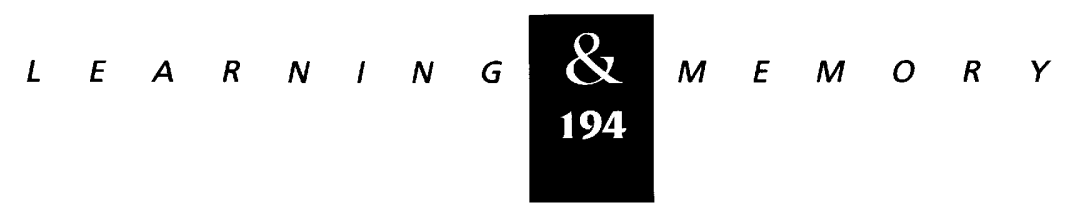


amount of BDNF immunostaining observed in these slices at later time points (data not shown) was sometimes within the range of levels observed at other flow rates that were effective in enhancing synaptic strength. This suggests that the rate at which BDNF is presented to the synaptic regions is perhaps more important than the absolute concentration in determining whether synaptic transmission will be enhanced.

The effects of BDNF on synaptic transmission and plasticity have been examined by several other groups. In cell cultures studies of nerve-muscle and hippocampal synapses (Lohof et al. 1993; Lessmann et al. 1994; Levine et al. 1995), BDNF has been shown to potentiate synaptic transmission within minutes of its application. Clearly, BDNF's access to the relevant synaptic sites is not a problem for culture studies that use cell monolayers to study synaptic transmission. This may explain why rapid effects have been observed readily in cell culture.

Two recent studies have shown that both homozygous and heterozygous BDNF knockout mice exhibit compromised long-term potentiation (LTP) (Korte et al. 1995; Patterson et al. 1996). Patterson et al. (1996) attempted to rescue the deficit in both basal synaptic transmission and LTP by treating slices from mutant mice with BDNF. They reported that prolonged treatments with BDNF (5-8 hr) were required to rescue LTP in slices from the knockout mice and noted that these BDNF treatments did not enhance synaptic transmission. Another study published recently (Figurov et al. 1996) has reported that BDNF application facilitates the induction of LTP in young animals, but does not enhance synaptic transmission independently. In the latter study, 2.5- to 3.0$\mathrm{hr}$ BDNF incubations were required to produce an effect on LTP.

There are two important variables worth noting. Both of these studies used interface type chambers in which only one surface of the slice was exposed directly to the BDNF-containing solution. The perfusion rates used were very slow $(10-25 \mathrm{ml} / \mathrm{hr})$. Immunocytochemical analysis in one of these studies (Patterson et al. 1996) indicated that BDNF did not penetrate the tissue substantially until after several hours of incubation. The combination of the interface chamber and the slow perfusion rate clearly can reduce dramatically the rate of BDNF delivery relative to the fast perfusion rate conditions described here and in our previous study (Kang and Schuman 1995b).
Moreover, the parametric manipulation of perfusion rate described in this paper further highlights the importance of the rate of BDNF delivery in determining whether synaptic potentiation will result. As indicated above, the slowest flow rate we examined $(25 \mathrm{ml} / \mathrm{hr})$, perhaps most similar to the slow delivery conditions employed by others, did not produce any potentiation of synaptic transmission, although our confocal studies indicated that a small amount BDNF penetrated the slice at this slow flow rate (Fig. 4C). In contrast, we showed that at a fast flow rate $(210 \mathrm{ml} / \mathrm{hr})$ a substantial quantity of BDNF reaches the interior of the slice within $15 \mathrm{~min}$ (Fig. 4E). This underscores again the importance of rate of BDNF delivery as a key variable in determining whether synaptic potentiation will result.

What is the molecular underpinning of the demonstrated dependence of the BDNF-induced potentiation on perfusion rate? BDNF application to cultured hippocampal cells (Berninger et al. 1993) and nerve-muscle cultures (Stoop and Poo 1996) has been shown to dramatically increase intracellular $\mathrm{Ca}^{2+}$. Our own studies indicate that $\mathrm{Ca}^{2+}$ influx through voltage-gated $\mathrm{Ca}^{2+}$ channels and intracellular $\mathrm{Ca}^{2+}$ stores is obligatory for the induction of the BDNF-induced potentiation (Kang and Schuman 1995a). It is therefore possible that a threshold concentration of intracellular $\mathrm{Ca}^{2+}$ must be reached to initiate the neurotrophin-induced enhancement. Moreover, the magnitude of the $\mathrm{Ca}^{2+}$ increase may determine the degree to which $\mathrm{Ca}^{2+}$ activates downstream effectors, and consequently influence the overall magnitude of the synaptic potentiation. Therefore, small quantities of BDNF that reach the synapse slowly may bind available Trk B receptors but fail to raise $\mathrm{Ca}^{2+}$ to sufficient levels to initiate synaptic enhancement. Trk receptors are known to be internalized following the binding of a neurotrophin (Hendry et al. 1974). As such, an additional effect of slow BDNF delivery may be to decrease the availability of Trk B receptors for subsequent BDNF that reaches the synapse. Taken together, it appears imperative that future attempts to observe BDNF-induced potentiation confirm that the experimental methods employed achieve a rapid (e.g., $\leqslant 30 \mathrm{~min}$ ) and substantial delivery of BDNF to the depths of the slice preparation.

\section{Acknowledgments}

This work was supported by funds from the Sloan

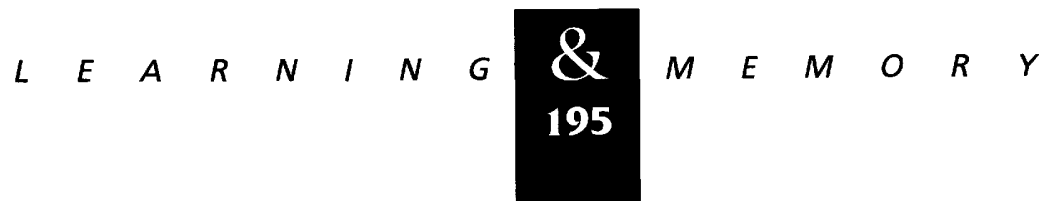




\section{Kang et al.}

Foundation, John Merck Fund, and Pew Charitable Trusts to E.M.S.

The publication costs of this article were defrayed in part by payment of page charges. This article must therefore be hereby marked "advertisement" in accordance with 18 USC section 1734 solely to indicate this fact.

\section{References}

Berninger, B., D.E. Garcia, N. Inagaki, C. Hahnel, and D. Lindholm. 1993. BDNF and NT-3 induce intracellular $\mathrm{Ca}^{2+}$ elevation in hippocampal neurones. NeuroReport 4: 1303-1306.

Escandon, E., D. Soppet, A. Rosenthal, J.L. Mendoza-Ramirez, E. Szonyi, L.E. Burton, C.E. Henderson, L.F. Parada, and K. Nikolics. 1994. Regulation of neurotrophin expression during embryonic and postnatal development. J. Neurosci. 14: 2054-2068.

Figurov, A., L.D. Pozzo-Miller, P. Olafsson, T. Wang, and B. Lu. 1996. Regulation of synaptic responses to high-frequnecy stimulation and LTP by neurotrophins in the hippocampus. Nature 381: 706-709.

Goodman, C.S. and C.J. Shatz. 1993. Developmental mechanisms that generate precise patterns of neuronal connectivity. Neuron/Cell 10: 77-98.

Hendry, I.A., K. Stockel, H. Thoenen, and L.L. Iversen. 1974. The retrograde axonal transport of nerve growth factor. Brain Res. 68: 103-121.

Ip, N.Y., Y. Li, G.D. Yancopoulos, and R.M. Lindsay. 1993. Cultured hippocampal neurons show responses to BDNF, NT-3, and NT-4, but not NGF. J. Neurosci. 13: 3394-3405.

Kang, H. and E.M. Schuman. 1995a. Characterization of neurotrophin-induced synaptic potentiation in area CA1 of the rat hippocampus. Soc. Neurosci. Abs. 21: 599.

1995b. Long-lasting neurotrophin-induced enhancment of synaptic transmission in the adult hippocampus. Science 267: 1658-1662.

1996. A requirement for local protein synthesis in neurotrophin-induced hippocampal synaptic plasticity. Science (in press).

Kase, H., K. Iwahashi, S. Nakanishi, Y. Matsuda, K. Yamada, M. Takahashi, C. Murakata, A. Sato, and M. Kaneko. 1987. K-252 compounds, novel and potent inhibitors of protein kinase $\mathrm{C}$ and cyclic nucleotide-dependent protein kinases. Biochem. Biophys. Res. Commun. 142: 436-440.

Korte, M., P. Carroll, E. Wolf, E. Brem, H. Thoenen, and T Bonhoeffer. 1995. Hippocampal long-term potentiation is impaired in mice lacking brain-derived neurotrophic factor. Proc. Natl. Acad. Sci. 92: 8856-8860.

Leibrock, J., F. Lottspeich, A. Hohn, M. Hofer, B. Hengerer, P. Masiakowski, H. Thoenen, and Y.-A. Barde. 1989. Molecular cloning and expression of brain-derived neurotrophic factor. Nature 341: 149-152.
Lessmann, V., K. Gottmann, and R. Heumann. 1994. BDNF and NT-4/5 enhance glutamatergic synaptic transmission in cultured hippocampal neurones. NeuroReport 6: 21-25.

Levine, E.S., C.F. Dreyfus, I.B. Black, and M.R. Plummer. 1995. Brain-derived neurotrophic factor rapidly enhances synaptic transmission in hippocampal neurons via postsynaptic tyrosine kinase receptors. Proc. Natl. Acad. Sci. 92: $8074-8078$.

Lo, D.C. 1995. Neurotrophic factors and synaptic plasticity. Neuron 15: 979-981.

Lohof, A.M., N. Ip, and M.-M. Poo. 1993. Potentiation of developing neuromuscular synapses by the neurotrophins NT-3 and BDNF. Nature 363: 350-353.

Merlio, J.P., P. Ernfors, M. Jaber, and H. Persson. 1992. Molecular cloning of rat trkC and distribution of cells expressing messenger mRNAs for members of the trk family in the rat central nervous system. Neuroscience 51: 513-532.

Patterson, S.L., T. Abel, T.A.S. Deuel, K.C. Martin, J.C. Rose, and E. Kandel. 1996. Recombinant BDNF rescues deficits in basal synaptic transmission and hippocampal LTP in BDNF knockout mice. Neuron 16: 1137-1145.

Stoop, R. and M.-M. Poo. 1996. Synaptic modulation by neurotrophic factors: Differential and synergistic effects of BDNF and CNTF. I. Neurosci. 16: 3256-3264.

Thoenen, H. 1995. Neurotrophins and neuronal plasticity. Science 270: 593-598.

Zhou, X.F., L.F. Parada, D. Soppet, and R.A. Rush. 1993. Localization of trkB kinase immunoreactivity in the rat central nervous system. Brain Res. 622: 63-70.

Received July 1, 1996; accepted in revised form August 19, 1996. 


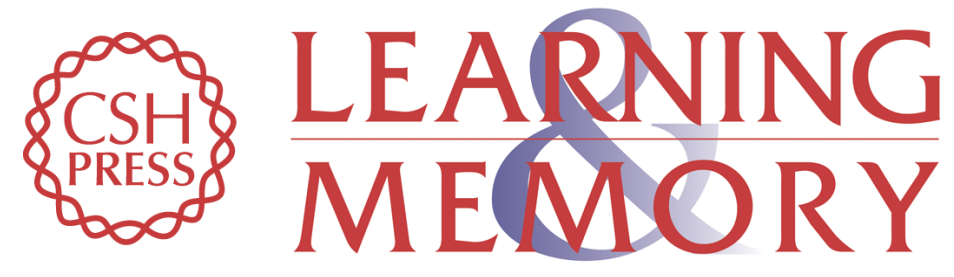

\section{Determinants of BDNF-induced hippocampal synaptic plasticity: role of the Trk $B$ receptor and the kinetics of neurotrophin delivery.}

H Kang, L Z Jia, K Y Suh, et al.

Learn. Mem. 1996, 3:

References This article cites 20 articles, 7 of which can be accessed free at:

http://learnmem.cshlp.org/content/3/2-3/188.full.html\#ref-list-1

License

Email Alerting

Service

Receive free email alerts when new articles cite this article - sign up in the box at the top right corner of the article or click here. 